ISSN = 1980-993X - doi:10.4136/1980-993X
www.ambi-agua.net
E-mail: ambi-agua@agro.unitau.br
Tel.: (12) 3625-4212

\title{
Análise morfométrica das sub-bacias hidrográficas Perdizes e Fojo no município de Campos do Jordão, SP, Brasil
}

(http://dx.doi.org/10.4136/ambi-agua.945)

\author{
Agenor Micaeli dos Santos ${ }^{1}$; Marcelo dos Santos Targa ${ }^{1}$; Getulio Teixeira Batista ${ }^{1}$; \\ Nelson Wellausen Dias ${ }^{2}$ \\ ${ }^{1}$ Departamento de Ciências Agrárias, Programa de Pós-Graduação em Ciências Ambientais \\ e-mails: agenormicaeli@yahoo.com.br,targa.marcelo@gmail.com,getulio@agro.unitau.br, \\ ${ }^{2}$ Instituto Brasileiro de Geografia e Estatística - IBGE \\ e-mail: nwdias@gmail.com
}

\section{RESUMO}

A Política de Recursos Hídricos do Estado de São Paulo estabeleceu em 1991 o Sistema Integrado de Gerenciamento de Recursos Hídricos (SIGRHI) e ao definir os princípios básicos para a gestão da água, adotou a bacia hidrográfica como unidade territorial para estudos, planejamento integrado para o desenvolvimento sustentável. O presente trabalho objetivou caracterizar a morfometria das sub-bacias hidrográficas Fojo e Perdizes, no município de Campos do Jordão, SP. A análise morfométrica envolveu a caracterização de parâmetros geométricos, do relevo, da rede de drenagem, e a análise do uso e ocupação do solo das sub-bacias. Na caracterização morfométrica foi encontrada para sub-bacia Perdizes a área de $12,70 \mathrm{~km}^{2}$, o perímetro de $19,85 \mathrm{~km}$ e o comprimento do eixo da bacia de $6,86 \mathrm{~km}$, enquanto para a sub-bacia Fojo, a área de drenagem encontrada foi de $13,97 \mathrm{~km}^{2}$, o perímetro de $19,74 \mathrm{~km}$ e o comprimento do eixo da bacia de $6,94 \mathrm{~km}$. Esses resultados indicam semelhanças entre as duas sub-bacias. O coeficiente de compacidade (Kc) encontrado, 1,56 para a sub-bacia Perdizes e 1,41 para a sub-bacia Fojo, associados aos respectivos fatores de forma, $\mathrm{F}=0,27$ e $\mathrm{F}=0,29$ indicam que estas sub-bacias, em condições normais de precipitação, são pouco suscetíveis a enchentes. $\mathrm{O}$ resultado desses índices é reforçado pelo índice de circularidade encontrado, IC $=0,41$ para Perdizes e IC $=0,45$ para Fojo, pois o afastamento da unidade indica que as sub-bacias não tendem à forma circular, ou seja, possuem forma mais alongada e, portanto, possuem menor concentração de deflúvio. Os resultados obtidos para o Coeficiente de manutenção $(\mathrm{Cm})$ indicam que para manter cada metro de canal, são necessários 286,5 $\mathrm{m}^{2}$ para Perdizes e 243,9 $\mathrm{m}^{2}$ para Fojo. A análise do uso e ocupação do solo revelou que dos quatro tipos de coberturas vegetais existentes: a cobertura vegetal dominante nas duas sub-bacias é de Floresta com 649 ha $(51,1 \%)$ na Perdizes e 608,8 ha $(43,6 \%)$ na Fojo; a cobertura Reflorestamento aparece em segundo lugar, ocupa área muito semelhante nas duas sub-bacias, 218 ha $(17,2 \%)$ na Perdizes e aproximadamente 214 ha $(15,3 \%)$ na Fojo. Em termos de conservação, a sub-bacia Fojo apresenta-se melhor conservada, pois além de menor área urbanizada, apresenta ainda, maior área com cobertura do tipo campo e uma área de floresta apenas um pouco menor que da sub-bacia Perdizes.

Palavras-chave: drenagem, uso do solo, escoamento superficial, manejo de bacias.

\section{Morphometric analysis of sub-basins Fojo and Perdizes in the city of Campos do Jordão, SP, Brazil}

\section{ABSTRACT}

The State of São Paulo Water Resources Policy established, in 1991, the Integrated Water Resources Management System (SIGRHI) and defined the basic principles for water 
management, adopting the watershed as the basic unit for studies, integrated planning for sustainable development. This study characterized the morphology of sub-basins Fojo and Perdizes in the city of Campos do Jordão, SP. Morphometric analysis involved the characterization of geometric parameters, topography and drainage network, and the analysis of land use and land cover of the sub-basins. The morphometric characterization revealed that Perdizes sub-basin has an area of $12.70 \mathrm{~km}^{2}$, a perimeter of $19.85 \mathrm{~km}$, and a main channel length of $6.86 \mathrm{~km}$, while Fojo sub-basin has a drainage area of $13.97 \mathrm{~km}^{2}$, a perimeter of $19.74 \mathrm{~km}$, and a main channel length of $6.94 \mathrm{~km}$. These results indicate similarities between the two sub-basins. The compactness coefficient $(\mathrm{Kc})$ for Perdizes was 1.56 and for Fojo 1.41. These values associated with the respective form factors, $F=0.27$ and $F=0.29$, indicate that these sub-basins, under a normal precipitation regime are not susceptible to flooding. The results of these indices are consisted with the circularity index $(\mathrm{CI})$ found: $\mathrm{CI}=0.41$ for Perdizes and $\mathrm{CI}=0.45$ for Fojo, respectively. As CI values found are far from one, they indicate that these sub-basins tend to have a more elongated shape and, therefore, lower flow concentration tendency. The results obtained for the maintenance coefficient indicate that in order to maintain the flow of each channel meter, Perdizes sub-basin needs $286.5 \mathrm{~m}^{2}$ and Fojo sub-basin needs $243.9 \mathrm{~m}^{2}$. Land cover and land use analysis revealed that among the four existing vegetation cover types, Forest is dominant in both sub-basins with 649 ha $(51.1 \%)$ in Perdizes, and 608.8 ha (43.6\%) in Fojo; Reforestation cover ranks second with similar areas in both sub-basins, Perdizes with 218 ha (17.2\%) and Fojo with approximately 214 ha $(15.3 \%)$. In terms of conservation, Fojo sub-basin can be considered better conserved with a smaller urban area, larger rangeland natural coverage area, and only slightly smaller forest coverage area than Perdizes.

Keywords: drainage, land use, runoff, watershed management.

\section{INTRODUÇÃO}

A Política de Recursos Hídricos no Estado de São Paulo (Lei Estadual 7663/91) estabeleceu uma divisão hidrográfica composta por 21 Unidades de Gerenciamento de Recursos Hídricos (UGRHIs) e o abastecimento público como prioridade no uso da água (São Paulo, 1991). A unidade Serra da Mantiqueira (UGRHI I) é composta pelos municípios de São Bento do Sapucaí, Santo António do Pinhal e Campos do Jordão que integram o Comitê das Bacias Hidrográficas da Serra da Mantiqueira (CBH-SM).

No município de Campos do Jordão, a bacia mais importante é a do rio Capivari, integrada pelas sub-bacias dos afluentes: rio Abernéssia, os ribeirões Imbiri, Perdizes, Fojo e os córregos Mato Grosso e Homem Morto (CBH-SM, 2009). Destes os principais mananciais de captação de água para o abastecimento público para o município de Campos do Jordão são as sub-bacias dos ribeirões Perdizes e Fojo.

O comportamento hidrológico de uma bacia hidrográfica é função de suas características geomorfológicas (forma, relevo, área, geologia, rede de drenagem, solo, dentre outros) e do tipo da cobertura vegetal (Lima, 1986). As características físicas e também as bióticas, principalmente àquelas relacionadas com a cobertura vegetal do solo desempenham importante papel nos processos relacionados à fase terrestre do ciclo hidrológico, influenciando, dentre outros, a infiltração, a evapotranspiração e os escoamentos superficial e subsuperficial e a quantidade de água produzida como deflúvio.

Segundo Kobiyama (2000), os ecossistemas florestais constituídos por parte aérea (árvores) e parte terrestre (solos florestais) desempenham a seguintes funções: (1) mitigação do clima (temperatura e umidade); (2) diminuição do pico do hidrograma (redução de enchentes e aumento da recarga para os rios); (3) controle de erosão; (4) melhoramento da 
qualidade da água no solo e no rio; (5) atenuação da poluição atmosférica; (6) fornecimento do oxigênio $(\mathrm{O} 2)$ e absorção do gás carbônico $(\mathrm{CO} 2)$; (7) prevenção contra ação do vento e ruídos; (8) recreação e educação; (9) produção de biomassa e (10) fornecimento de energia.

O município de Campos do Jordão foi em 2000 caracterizado como o que possuía mais áreas com risco de desabamentos e, portanto, foi classificado em termos de presença de áreas de risco, na faixa entre alto e muito alto risco (IPT, 2003).

A cobertura vegetal nativa do Estado de São Paulo, em especial por ser a mais afetada pelas atividades antrópicas, diminuiu consideravelmente, encontrando-se perto dos $15 \%$ da sua extensão territorial original (Kronka et al., 2005). Nesse sentido, o aumento da população, os processos de urbanização e agricultura entre outras atividades antrópicas se constituem nas principais causas da redução das florestas, redução da água dos mananciais e pode colocar em risco a garantia de oferta de água para as gerações atuais e futuras.

Com relação a atividades antrópicas em bacias, Curvello et al. (2008) em estudo sobre o rio Batedor na Serra da Mantiqueira no município de Cruzeiro, SP, concluíram que sua bacia apresentava características físicas favoráveis ao abastecimento hídrico por ser bem drenada, com grande disponibilidade hídrica, não apresentar risco de enchentes e estar situada em área de muitas nascentes, na encosta da Serra da Mantiqueira, e possuir cursos jovens, com pouca sinuosidade.

As sub-bacias Fojo e Perdizes, no município de Campos do Jordão, SP, na região Serrana do Vale do Paraíba, devido aos problemas advindos do uso e ocupação do solo desordenados, têm recebido recomendações de cuidados relativos à contaminação por efluentes domésticos e criticidade para abastecimento público (CBH-SM, 2009).

As características físicas de uma bacia constituem elementos de grande importância para avaliação de seu comportamento hidrológico, pois, ao se estabelecerem relações e comparações entre elas e os dados hidrológicos conhecidos, pode-se determinar, indiretamente, os valores hidrológicos em locais em que esses dados são desconhecidos (Villela e Mattos, 1975). Por outro lado, para estudos das características de relevo importantes nas bacias hidrográficas deve-se priorizar o uso de métodos quantitativos, pois qualitativamente, os aspectos de forma são insuficientes para a identificação de fatores que influenciam as formas de relevo (Alves e Castro, 2003).

O estudo morfométrico de bacias hidrográficas é definido como a análise quantitativa das relações entre a fisiografia da bacia e a sua dinâmica hidrológica. A análise de parâmetros morfométricos tem grande importância nesses estudos, pois por meio da abordagem quantitativa, pode-se ter uma melhor noção do comportamento hidrológico, uma vez que, os parâmetros morfométricos são bons indicadores da capacidade de escoamento superficial (Nunes et al., 2006).

A área da bacia hidrográfica, por exemplo, tem influência sobre a quantidade de água produzida como deflúvio. A forma e o relevo, no entanto, atuam sobre a taxa ou sobre o regime dessa produção de água, assim como sobre a taxa de sedimentação. O caráter e a extensão dos canais (padrão de drenagem) afetam a disponibilidade de sedimentos, bem como a taxa de formação do deflúvio (Lima, 1986).

Neste contexto, o presente trabalho objetivou analisar a morfometria das sub-bacias dos ribeirões Perdizes e Fojo, afluentes do rio Capivari, utilizados na captação e abastecimento de água para consumo humano no município de Campos do Jordão. 


\section{MATERIAL E MÉTODOS}

\subsection{Caracterização da área de estudo}

Campos do Jordão, com uma área de $290 \mathrm{~km}^{2}$, localiza-se no estado de São Paulo, em um platô a $1.600 \mathrm{~m}$ acima do nível do mar, na Serra da Mantiqueira, distante $167 \mathrm{~km}$ da capital paulista. O município pertence à região administrativa de São José dos Campos, região de governo de Taubaté, no médio Vale do Paraíba, com uma população, em 2010, de 47.504 habitantes (IBGE, 2010). É um dos sete municípios do estado de São Paulo que integram a APA da Mantiqueira. A topografia é bastante acidentada com cerca de $85 \%$ do município composto por regiões onduladas, $10 \%$ por encostas de serra e $5 \%$ por áreas escarpadas. A área urbana da cidade está localizada em um vale com uma parte plana que não ultrapassa 500 metros de largura, contudo, alguns pontos o relevo atinge mais de 2.000 metros de altitude.

A área do presente estudo contempla as sub-bacias hidrográficas dos ribeirões Perdizes e Fojo, localizadas as coordenadas UTM dos cantos, inferior esquerdo E=430.000, $\mathrm{N}=7.480 .000$ e, superior direito $\mathrm{E}=460.000, \mathrm{~N}=7.550 .000$, Datum horizontal SAD-69 e Meridiano Central $45^{\circ} \mathrm{W}$, no município de Campos do Jordão, SP.

As sub-bacias Perdizes e Fojo são pareadas e a demarcação de suas áreas com o estabelecimento dos divisores de águas para a realização da análise morfométrica foi feita com base em fotografias aéreas, mapas temáticos e cartas do Instituto Brasileiro de Geografia e Estatística (IBGE).

Os dados pluviométricos da região de estudo são originários de uma série de dados de 30 anos do posto meteorológico de prefixo D2-096, situado no município de Campos do Jordão, SP e foram obtidos junto ao Banco de Dados Hidrometeorológicos do Estado de São Paulo (São Paulo, 1999). A partir desses dados foi possível estabelecer, para o período de 1972 a 2002, as precipitações mensais máxima, mínima e média (Figura 1), bem como os totais anuais (Figura 2).

Segundo Setzer (1966), o clima dessa região é do tipo Cfb caracterizado pela Classificação Climática do Sistema Internacional de Köeppen, e apresenta um período menos úmido de abril a setembro e um período chuvoso de outubro a março.

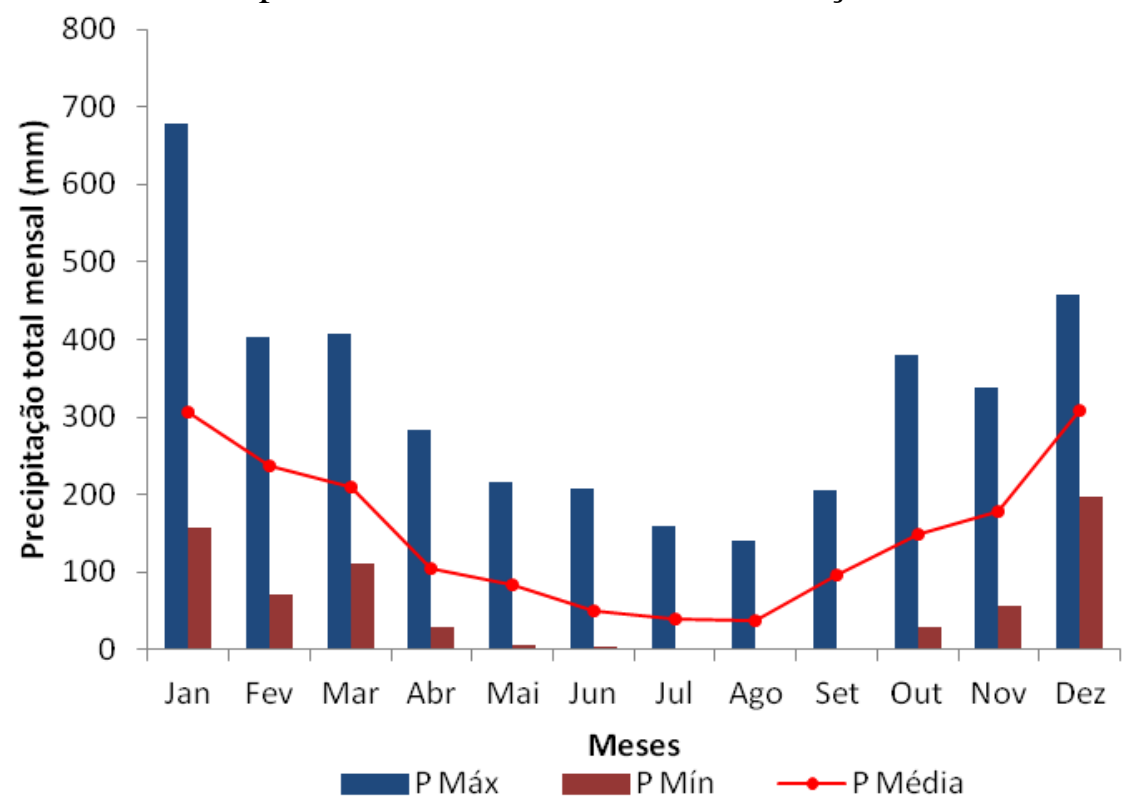

Figura 1. Precipitação mensal mínima, máxima e média para Campos do Jordão, SP, compiladas para o período de 1972 a 2002.

Fonte: (São Paulo, 1999). 


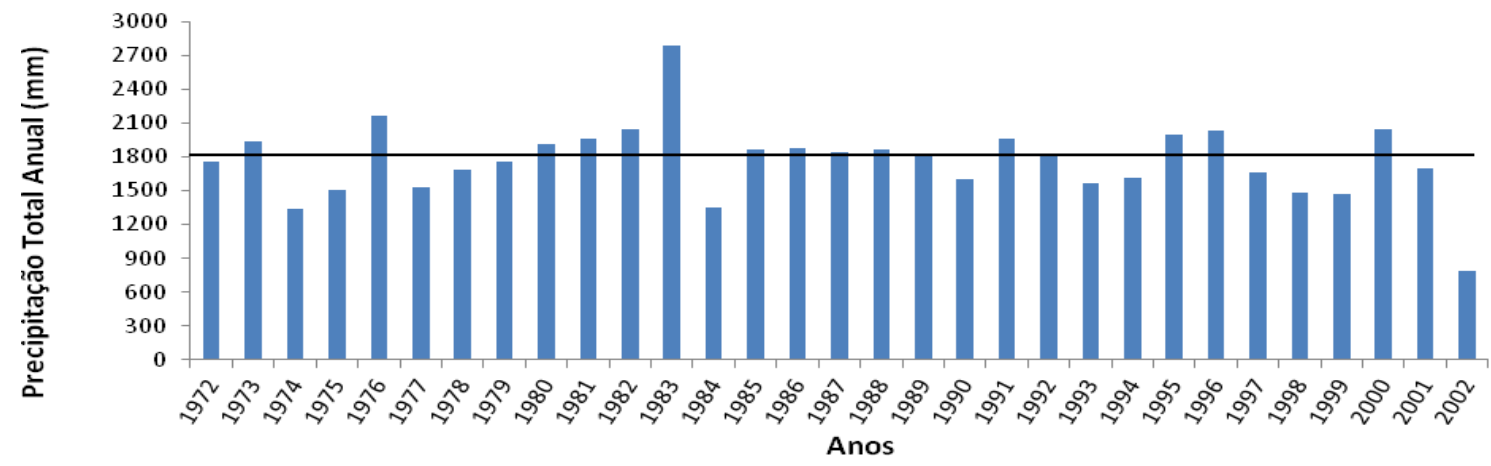

Figura 2. Precipitação Total Anual (mm) de Campos do Jordão, SP, no período de 1972 a 2002.

Fonte: (São Paulo, 1999).

\subsection{Análise morfométrica}

A análise morfométrica das sub-bacias hidrográficas foi feita a partir das características geométricas, de relevo, e das características da rede de drenagem.

$\mathrm{Na}$ caracterização geométrica foram determinados a área, o perímetro, o coeficiente de compacidade (Kc), o fator de forma (F), o índice de circularidade (IC), a densidade hidrográfica $(\mathrm{Dh})$, o número de canais de $1^{\mathrm{a}}$ ordem e o comprimento do eixo da bacia.

O coeficiente de compacidade $(\mathrm{Kc})$, que relaciona a forma da bacia com um círculo, é um número adimensional que varia com a forma da bacia, independente de seu tamanho. De modo que quanto maior a irregularidade da bacia maior será o coeficiente de compacidade. Como o coeficiente de compacidade igual à unidade corresponde a uma bacia circular, ele possibilita a indicação de maior ou menor ocorrência de cheias à medida que se aproxima ou afasta da unidade (Villela e Mattos, 1975). A determinação do Kc pode ser feita por meio da Equação [1]:

$$
K c=0,28 x \frac{P}{\sqrt{A}}
$$

em que:

$\mathrm{Kc}=$ Coeficiente de compacidade adimensional;

$\mathrm{P}=$ Perímetro da bacia em $\mathrm{km}$;

$\mathrm{A}=$ Área da bacia em $\mathrm{km}^{2}$.

O fator de forma (F) relaciona a forma da bacia com um retângulo, correlacionando a razão entre a largura média e o comprimento axial da bacia da foz até o ponto mais distante do espigão. Villela e Mattos (1975) citam que uma bacia com fator de forma baixo é menos suscetível a enchentes.

Para determinar o fator de forma foi utilizada a Equação [2]:

$$
F=\frac{A}{L^{2}}
$$

em que:

$\mathrm{F}=$ Fator de forma, adimensional;

$\mathrm{A}=$ Área da bacia em $\mathrm{km}^{2}$;

$\mathrm{L}=$ comprimento axial da bacia em $\mathrm{km}$. 
O índice de circularidade (IC) relaciona a área da bacia com a área de um círculo de perímetro igual ao da área da bacia. Este valor tende para unidade à medida que a bacia se aproxima da forma circular e diminui conforme a mesma se torna mais alongada (Cardoso et al., 2006).

Para se determinar o índice de circularidade utilizou-se a Equação [3]:

$$
I C=\frac{12,57 x A}{P^{2}}
$$

em que:

IC = Índice de Circularidade, adimensional;

$\mathrm{A}=$ Área da bacia em $\mathrm{km}^{2}$;

$\mathrm{P}=$ Perímetro da bacia em $\mathrm{km}$.

A densidade hidrográfica $(\mathrm{Dh})$ relaciona o número de rios ou canais com a área da bacia. Este índice expressa a grandeza da rede hidrográfica da bacia, indicando a capacidade de gerar novos cursos d'águas (Christofoletti, 1969).

Conforme Silva et al. (2002), o sistema de drenagem de uma bacia pode ser facilmente alterado, bastando uma pequena mudança de gradiente de descarga do rio motivada, por exemplo, por pequenos ajustes neotectônicos e/ou a elevação súbita da descarga da bacia, em razão de enxurradas associadas ao desmatamento em grande escala, na montante da bacia, os quais podem levar à erosão basal das margens côncavas, até a formação de barras de sedimentos, nas margens convexas, a jusante.

Para se determinar a densidade hidrográfica, foi utilizada a seguinte Equação [4]:

$$
D h=\frac{N}{A}
$$

em que:

$\mathrm{Dh}=$ Densidade hidrográfica;

$\mathrm{N}=$ Número de rios ou canais;

$\mathrm{A}=$ Área da bacia $\mathrm{em} \mathrm{km}^{2}$.

Christofoletti (1969) sugere a utilização de N como o número de canais de primeira ordem, conforme classificação de Strahler (1952), com o argumento de que isso conduz a resultados mais realistas sobre o comportamento hidrológico da bacia.

Lollo (1995) cita uma classificação da densidade hidrográfica em faixas de valores (Tabela 1).

Tabela 1. Classificação da densidade hidrográfica $(\mathrm{Dh})$ de bacias.

\begin{tabular}{c|c}
\hline $\begin{array}{c}\text { Dh } \\
\left(* \mathbf{N}_{\mathbf{1}} / \mathbf{k m}^{2}\right)\end{array}$ & Denominação \\
\hline$<3$ & Baixa \\
$3-7$ & Média \\
$7-15$ & Alta \\
$>15$ & Muito alta \\
\hline
\end{tabular}

$* \mathrm{~N}_{1}=$ Comprimento dos rios de primeira ordem conforme Strahler (1952).

Fonte: Lollo (1995). 
Para caracterização de relevo das sub-bacias foram determinados as altitudes máxima, mínima e média, a amplitude altimétrica, o índice de sinuosidade, o gradiente de canais e a relação de relevo.

A variação de altitude média é um fator muito importante, pois a temperatura e precipitação estão relacionadas com a altitude. Variações de temperatura influenciam as perdas de águas que ocorrem na forma de evaporação e transpiração, já variações na precipitação atuarão diretamente no escoamento superficial e infiltração (Villela e Mattos, 1975).

Para avaliação da altitude média foi utilizado o método descrito por Wisler e Brater (1964), no qual se calcula as subáreas existentes entres os pares de curvas de nível, depois se avalia as porcentagens destas subáreas em relação a área total da bacia. Por fim, por simples soma, calcula-se a porcentagem da área total que fica abaixo ou acima de determinada altitude. Com os dados de variação de altitude pode-se determinar a curva hipsométrica da bacia, que é a representação gráfica da variação de altitude em relação à área da bacia.

$\mathrm{O}$ índice de sinuosidade (Is) é a relação entre o comprimento do canal principal e a distância vetorial do canal principal. Este índice expressa a velocidade de escoamento do canal principal. Quanto maior a sinuosidade, maior será a dificuldade de se atingir o exutório do canal, portanto, a velocidade de escoamento será menor.

Segundo Freitas (1952), valores de Is próximos a unidade indicam canais retilíneos, valores de Is superiores a 2 indicam canais sinuosos e os valores intermediários indicam formas transicionais.

Para se determinar o índice de sinuosidade utilizou-se a Equação [5]:

$$
I s=\frac{L c}{L v}
$$

em que:

Is = Índice de sinuosidade, adimensional;

$\mathrm{Lc}=$ comprimento do canal principal em $\mathrm{km}$;

$\mathrm{Lv}=$ comprimento vetorial do canal principal em $\mathrm{km}$.

O gradiente de canais $(\mathrm{Gc})$ é dado pela relação entre a altitude máxima da bacia e o comprimento do canal principal. Este índice tem por finalidade indicar a declividade dos cursos d'água da bacia (Horton, 1945; Freitas, 1952).

Para se determinar o gradiente de canais, foi utilizada a Equação [6]:

$$
G c=\frac{A \max }{L c}
$$

em que:

$\mathrm{Gc}=$ Gradiente de canais em $\mathrm{m} / \mathrm{km}$;

Amax = altitude máxima da bacia em m;

$\mathrm{Lc}=$ comprimento do canal principal em $\mathrm{km}$.

A relação de relevo $(\mathrm{Rr})$ é a relação entre a amplitude altimétrica da bacia e o comprimento do canal principal. Segundo Schumm (1956), quanto maior o valor de Rr, maior será o desnível entre a cabeceira e o exutório, consequentemente maior será a declividade média da bacia.

Para o cálculo da relação de relevo foi utilizada a Equação [7]: 


$$
R r=\frac{H m}{L c}
$$

em que:

$\mathrm{Rr}=$ Relação de relevo em $\mathrm{m} / \mathrm{km}$;

$\mathrm{Hm}=$ amplitude altimétrica em $\mathrm{m}$;

$\mathrm{Lc}=$ comprimento do canal principal em $\mathrm{km}$.

A densidade de drenagem (Dd ) é a relação entre o comprimento total de canais e a área da bacia e para seu cálculo, devem-se considerar todos os rios tanto os perenes como os temporários (Horton, 1945). Para caracterização da rede de drenagem, foram determinados o comprimento do canal principal, o comprimento total dos canais, o comprimento vetorial do canal principal, a densidade de drenagem e a ordem da bacia.

Segundo Christofoletti (1969), valores elevados de Dd indicam áreas com pouca infiltração e melhor estruturação dos canais.

A densidade de drenagem (Dd) foi obtida por meio da Equação [8]:

$$
D d=\frac{L t}{A}
$$

em que:

$\mathrm{Lt}=$ comprimento total dos canais;

$\mathrm{A}=$ Área da bacia.

Beltrame (1994) sugeriu uma classificação em faixas para a densidade de drenagem (Tabela 2).

Tabela 2. Classificação da densidade de drenagem (Dd) de uma bacia.

\begin{tabular}{c|c}
\hline $\begin{array}{c}\text { Dd } \\
\left(\mathbf{k m} / \mathbf{k m}^{2}\right)\end{array}$ & Denominação \\
\hline$<0,50$ & Baixa \\
$0,50-2,00$ & Mediana \\
$2,01-3,50$ & Alta \\
$>3,50$ & Muito Alta \\
\hline
\end{tabular}

Fonte: Beltrame (1994).

A partir da densidade de drenagem é possível se calcular o Coeficiente de manutenção $(\mathrm{Cm})$, que representa a área necessária que a bacia deve ter para manter perene cada metro de canal de drenagem. O Coeficiente de manutenção $(\mathrm{Cm})$ é calculado pela Equação [9]:

$$
C m=\frac{1}{D d}
$$

em que:

$\mathrm{Cm}=$ Coeficiente de manutenção;

$\mathrm{Dd}=$ Densidade de drenagem.

A ordem dos cursos d'água da bacia foi determinada utilizando-se a metodologia descrita por Strahler (1952), em que os canais sem tributários são denominados de primeira ordem, os 
canais de segunda ordem são originados na confluência de canais de primeira ordem, os canais de terceira surgem da confluência de dois canais de segunda ordem, os canais de quarta ordem são originados da confluência de dois canais de terceira ordem e assim sucessivamente. Dessa forma, quanto maior a ordem da bacia, maior será a ramificação do sistema de drenagem.

\subsection{Uso e ocupação do solo}

Na definição do uso e ocupação do solo das sub-bacias Perdizes e Fojo foram utilizadas fotografias aéreas verticais do município de Campos do Jordão, provenientes de aerolevantamento fotográfico na escala 1: 25.000 realizado em abril de 2003 e ortofotos da coleção de fotos do Comitê de Bacias Hidrográficas da Serra da Mantiqueira - CBH-SM, disponíveis em modo digital, com resolução espacial de $60 \mathrm{~cm}$.

A partir das ortofotos e utilizando o aplicativo de Sistema de Informação Geográfica (SIG) da ESRI, ArcGis 9.0, Santos et al. (2011) geraram um mapa temático de uso do solo para campos do Jordão, SP, a partir de recorte feito no mapa de uso e ocupação do solo da região elaborado pelo Instituto Florestal de São Paulo (Figura 3). Para este estudo foi feito um recorte desse mapa utilizando os limites das sub-bacias definidos anteriormente. As classes originais foram reagrupadas em floresta, reflorestamento, campo, pasto, área urbanizada e outros para melhor atender às necessidades deste estudo.

\subsection{Caracterização do solo}

No município de Campos do Jordão, os latossolos LVA9 e LVA18 encontram-se em pequenas quantidades, enquanto o cambissolo CX14 ocupa a maior e principal área do município, incluindo a área das duas sub-bacias em estudo (Santos et al., 2011).

A classificação do solo da área de estudo foi feita a partir de um recorte no Mapa de Solos do Brasil, o qual é resultado da parceria entre o Instituto Brasileiro de Geografia e Estatística - IBGE e o Centro Nacional de Pesquisas de Solos da Embrapa (IBGE, 2002). A classe dos Latossolos constitui o agrupamento de solos mais extenso do Estado de São Paulo. Em geral, são solos com boas propriedades físicas e situados, na maioria dos casos, em relevo favorável ao uso intensivo de máquinas agrícolas, com exceção dos solos em regiões serranas. Segundo Reatto et al. (1999), os Latossolos possuem, geralmente, elevada permeabilidade e a sua capacidade máxima de armazenamento de água pode, em média, variar de 260 a $330 \mathrm{~mm}$ para solos de textura média, de 300 a 500mm para solos de textura argilosa e de 500 a 760 mm para os solos de textura muito argilosa.

Já os Cambissolos, segundo Oliveira (1999), situam-se em relevo forte ondulado a escarpado e apresentam severas restrições quanto ao uso agrícola. Aqueles localizados em terrenos escarpados apresentam maior limitação de uso, mesmo ao uso pastoril e florestal, devido à sua capacidade de desagregação. Tais solos possuem elevada erodibilidade e forte limitação à trafegabilidade, à qual é aumentada com a pedregosidade e afloramentos de rocha e pela presença de solos rasos representados pelos Neossolos Litólicos. É comum a presença de solos apresentando horizonte $\mathrm{Cr}$ (saprolito) constituído por rocha parcialmente intemperizada a profundidades inferiores a $1,5 \mathrm{~m}$.

\section{RESULTADOS E DISCUSSÃO}

A quantidade das áreas de ocorrência dos diferentes tipos de cobertura vegetal e das áreas de ocupação urbanas nas sub-bacias Perdizes e Fojo, com a definição das classes de uso utilizadas nesse trabalho, foram adaptados do mapa de uso e ocupação do solo elaborado por Santos et al. (2011). 
A análise do uso e ocupação do solo das sub-bacias em estudo, revelou que dos quatro tipos de coberturas vegetais existentes: Campo, Floresta, Pasto e Reflorestamento, a cobertura vegetal dominante nas duas sub-bacias é de Floresta (vegetação secundária em estágio médio) com 649 ha $(51,1 \%)$ na Perdizes e 608,8 ha $(43,6 \%)$ na Fojo; a cobertura Reflorestamento aparece em segundo lugar, ocupa área muito semelhante nas duas sub-bacias, 218 ha $(17,2 \%)$ na Perdizes e aproximadamente 214 ha $(15,3 \%)$ na Fojo; o Campo (campo natural com/sem perturbação antrópica) não aparece como uso e cobertura na sub-bacia Perdizes. Por outro lado o Campo ocupa uma área de 265 ha, quase 19\% da sub-bacia Fojo. A cobertura vegetal denominada de Pasto apresenta uma área de 79,8 ha $(6,3 \%)$ na Perdizes e 47 ha $(3,4 \%)$ na Fojo.

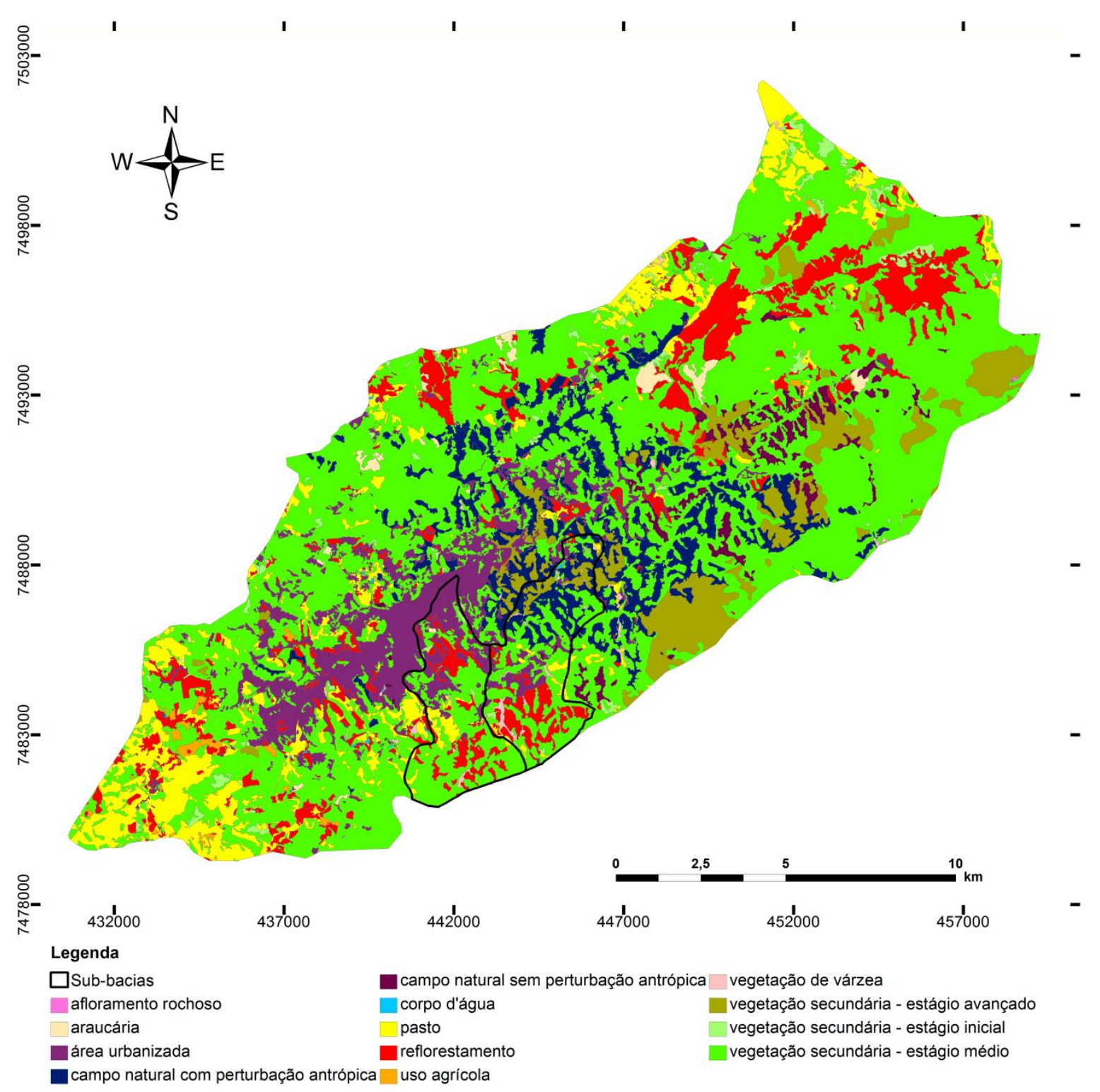

Figura 3. Mapa temático de uso e ocupação do solo do município de Campos do Jordão.

Fonte: Adaptado por Santos et al. (2011).

Atenção especial deve ser dada à classe de uso do solo Área Urbanizada, a qual possui o maior significado antrópico nas sub-bacias, e que no total ocupa 434 ha, sendo que na subbacia Perdizes é de aproximadamente 300 ha $(23,8 \%)$ e na sub-bacia Fojo está acima de 130 ha $(9,5 \%)$. 
Segundo o Instituto de Pesquisa Tecnológica (IPT, 2003), a área do município de Campos do Jordão é de $28.790,35$ ha, enquanto a área total das sub-bacias em estudo corresponde a 2.666 ha $(9,26 \%)$, sendo $4,41 \%$ para a sub-bacia Perdizes e $4,85 \%$ para a subbacia Fojo. Conforme pode ser observado na Figura 4, que apresenta a rede de drenagem, as duas sub-bacias integram o sistema de abastecimento público de Campos do Jordão e são utilizadas pela SABESP. A captação de água é feita em três locais, dois na sub-bacia Perdizes (sendo um mais a montante na bacia, no ribeirão do Salto e outro mais a jusante no próprio ribeirão Perdizes) onde é captada uma vazão de $72 \mathrm{~L} / \mathrm{s}$, e a terceira na sub-bacia Fojo, onde é captada uma vazão de $136 \mathrm{~L} / \mathrm{s}$ em um local mais a jusante conhecido como represa do Fojo (CBH-SM, 2009). As áreas dessas sub-bacias têm sido submetidas a processos diferenciados de uso e ocupação que interferem na dinâmica da água na bacia, o que reforça os resultados obtidos por Santos et al. (2011) para essas bacias com relação as suas capacidades de infiltração e de perdas por escoamento superficial.

Com essas duas captações de água para abastecimento do município, torna-se necessário a implementação de ações de conservação em médio e curto prazo para minimizar possíveis problemas de desabastecimento no município, pois a sub-bacia Perdizes apresenta um menor estado de conservação, uma vez que possui área urbanizada 2,3 vezes maior e não apresenta cobertura vegetal do tipo campo.

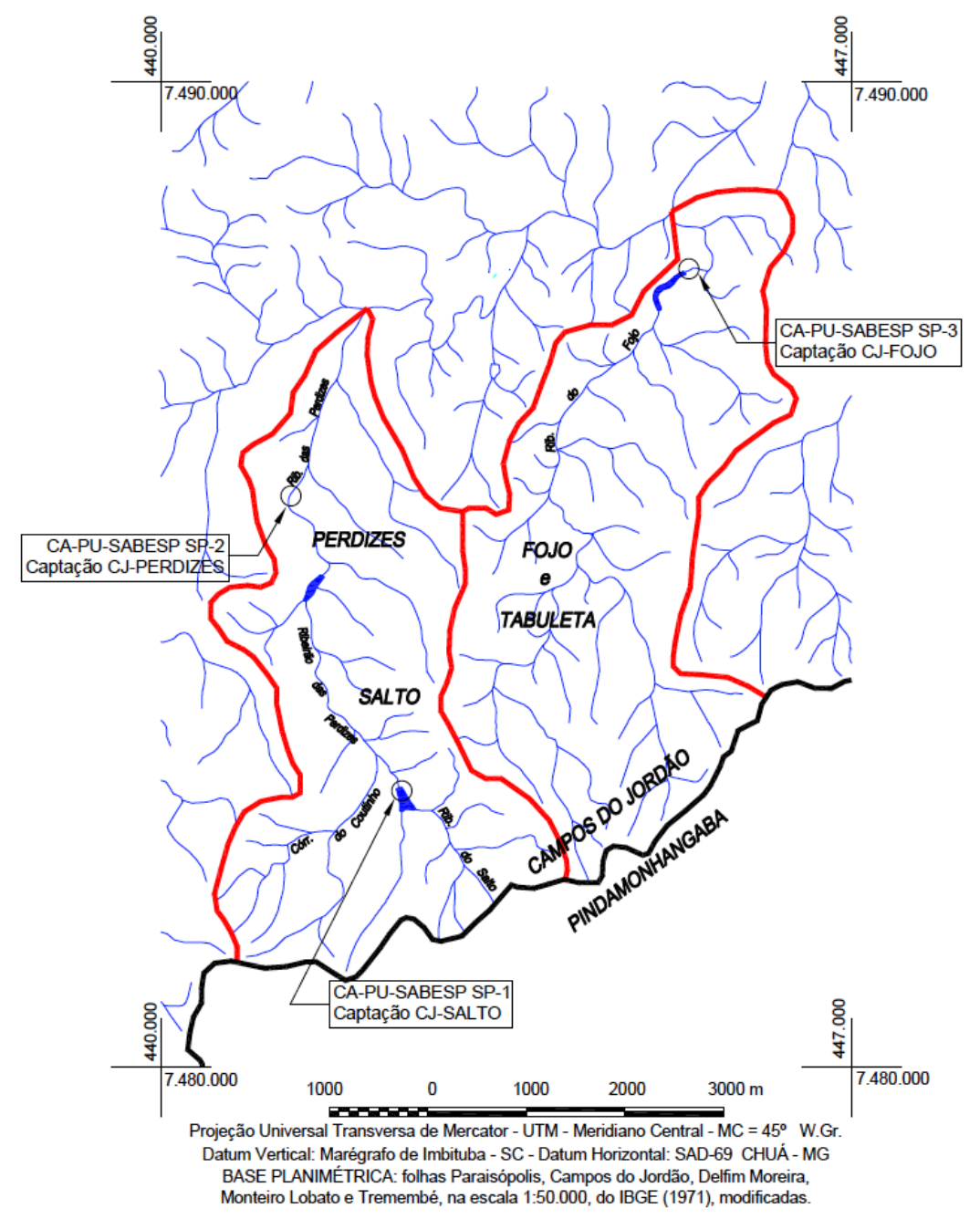

Figura 4. Rede de drenagem das sub-bacias Perdizes e Fojo com destaque para os pontos de captação de água para abastecimento público.

Fonte: Santos et al. (2011). 
SANTOS, A. M.; TARGA, M. S.; BATISTA, G. T.; DIAS, N. W. Análise morfométrica das sub-bacias hidrográficas Perdizes e Fojo no município de Campos do Jordão, SP, Brasil. Ambi-Agua, Taubaté, v. 7, n. 3, p. 195-211, 2012. (http://dx.doi.org/10.4136/ambi-agua.945)

A caracterização morfométrica das sub-bacias Perdizes e Fojo é apresentada na Tabela 3.

Tabela 3. Características morfométricas das sub-bacias Perdizes e Fojo.

\begin{tabular}{|c|c|c|c|c|}
\hline \multirow[b]{3}{*}{$\begin{array}{l}\text { Características } \\
\text { geométricas }\end{array}$} & \multirow{2}{*}{ Características morfométricas } & \multirow{2}{*}{ Unidades } & \multicolumn{2}{|c|}{ Sub-bacias } \\
\hline & & & Perdizes & Fojo \\
\hline & $\begin{array}{l}\text { Área } \\
\text { Perímetro } \\
\text { Número de canais de } 1^{\text {a }} \text { ordem } \\
\text { Comprimento do eixo da bacia } \\
\text { Coeficiente de compacidade (Kc) } \\
\text { Fator de forma (F) } \\
\text { Índice de circularidade (IC) } \\
\text { Densidade hidrográfica (Dh) }\end{array}$ & $\begin{array}{c}\mathrm{km}^{2} \\
\mathrm{~km} \\
- \\
\mathrm{km} \\
- \\
- \\
- \\
\text { canais/km² }\end{array}$ & $\begin{array}{r}12,70 \\
19,85 \\
78 \\
6,86 \\
1,56 \\
0,27 \\
0,41 \\
6,14\end{array}$ & $\begin{array}{r}13,97 \\
19,74 \\
116 \\
6,94 \\
1,48 \\
0,29 \\
0,45 \\
8,30\end{array}$ \\
\hline $\begin{array}{l}\text { Características } \\
\text { do relevo }\end{array}$ & $\begin{array}{l}\text { Altitude máxima } \\
\text { Altitude média } \\
\text { Altitude mínima } \\
\text { Amplitude altimétrica }(\mathrm{Hm}) \\
\text { Índice de sinuosidade }(\mathrm{Is}) \\
\text { Gradiente dos canais }(\mathrm{Gc}) \\
\text { Relação de relevo }(\mathrm{Rr})\end{array}$ & $\begin{array}{c}\mathrm{m} \\
\mathrm{m} \\
\mathrm{m} \\
\mathrm{m} \\
\mathrm{m} / \mathrm{m} \\
\% \\
\mathrm{~m} / \mathrm{km}\end{array}$ & $\begin{array}{r}1.910 \\
1.720 \\
1.580 \\
330 \\
1,33 \\
22 \\
37,5\end{array}$ & $\begin{array}{r}1.950 \\
1.734 \\
1.520 \\
430 \\
1,43 \\
20 \\
44,6\end{array}$ \\
\hline $\begin{array}{l}\text { Características } \\
\text { da rede de } \\
\text { drenagem }\end{array}$ & $\begin{array}{l}\text { Comprimento do canal principal } \\
\text { Comprimento total dos canais } \\
\text { Comprimento vetorial do canal principal } \\
\text { Densidade de drenagem (Dd) } \\
\text { Coeficiente de Manutenção }(\mathrm{Cm}) \\
\text { Ordem da bacia }\end{array}$ & $\begin{array}{c}\mathrm{km} \\
\mathrm{km} \\
\mathrm{km} \\
\mathrm{km} / \mathrm{km}^{2} \\
\mathrm{~m}^{2} / \mathrm{m} \\
-\end{array}$ & $\begin{array}{r}8,81 \\
44,27 \\
6,63 \\
3,49 \\
286,5 \\
4\end{array}$ & $\begin{array}{r}9,64 \\
57,34 \\
6,73 \\
4,10 \\
243,9 \\
4\end{array}$ \\
\hline
\end{tabular}

Em termos de caracterização geométrica (Tabela 3), foi encontrada para a sub-bacia Perdizes a área de $12,70 \mathrm{~km}^{2}$, o perímetro de $19,85 \mathrm{~km}$ e o comprimento do eixo da bacia de $6,86 \mathrm{~km}$, enquanto para a sub-bacia Fojo, a área de drenagem encontrada foi de $13,97 \mathrm{~km}^{2}$, o perímetro de $19,74 \mathrm{~km}$ e o comprimento do eixo da bacia de $6,94 \mathrm{~km}$. Esses resultados de morfometria indicam que há semelhanças entre as duas sub-bacias.

O coeficiente de compacidade (Kc) encontrado, 1,56 para a sub-bacia Perdizes e 1,41 para a sub-bacia Fojo, associados aos respectivos fatores de forma, $F=0,27$ e $F=0,29$ indicam que estas sub-bacias, em condições normais de precipitação, são pouco suscetíveis a enchentes. O resultado desses índices é reforçado pelo índice de circularidade (IC) encontrado, (IC $=0,41)$ para Perdizes e $(\mathrm{IC}=0,45)$ para Fojo, pois o afastamento da unidade indica que as sub-bacias não tendem à forma circular, ou seja, possuem forma mais alongada e, portanto, segundo Villela e Mattos (1975), possuem menor concentração de deflúvio.

A densidade hidrográfica indica a capacidade das sub-bacias gerarem novos canais e de acordo com Lana et al. (2001), se esse índice estiver acima de 2,00 canais $/ \mathrm{km}^{2}$, a bacia teria grande capacidade de gerar novos cursos d'água. No presente estudo foi encontrada densidade hidrográfica de 6,14 canais $/ \mathrm{km}^{2}$ para a sub-bacia Perdizes e 8,30 canais $/ \mathrm{km}^{2}$ para a sub-bacia Fojo, portanto, de acordo com os parâmetros (Tabela 1) estabelecidos em Lollo (1995), a subbacia Perdizes possui média densidade hidrográfica e a sub-bacia Fojo possui densidade hidrográfica considerada alta. O resultado maior na sub-bacia Fojo é reforçado por apresentar parâmetros de comprimento do canal principal e comprimento total de canais superiores ao da sub-bacia Perdizes, o que deve possibilitar maior facilidade de uma partícula de água que cai na superfície do solo encontrar rapidamente um canal e escoar.

Em termos de características do relevo (Tabela 3), a sub-bacia Perdizes apresenta altitude 
máxima e mínima de 1910 m e 1580 m, respectivamente, enquanto na sub-bacia Fojo esses valores atingem $1950 \mathrm{~m}$ e $1520 \mathrm{~m}$. Dessa forma, os valores encontrados para a Amplitude altimétrica $(\mathrm{Hm})$ foram de 330 para Perdizes e 430 para Fojo, o que indica que estas subbacias possuem relevo montanhoso, o que influencia na quantidade de radiação que a bacia hidrográfica recebe e, consequentemente, na evapotranspiração, na temperatura e na precipitação (Tonello et al., 2006). Os altos valores de amplitude altimétrica, como os observados, tendem a favorecer o escoamento rápido. Esses resultados são reforçados pelos elevados valores encontrados para o Gradiente de canais $(\mathrm{Gc})$ e para a Relação de relevo (Rr) nas duas sub-bacias.

A altitude média obtida, segundo a metodologia de Wisler e Bratter (1964), foi de 1.720 m para a sub-bacia Perdizes e de 1.734 m para a sub-bacia Fojo. Com os resultados da variação altimétrica, foi possível traçar a curva hipsométrica e obter-se, assim, um valor também importante que é a altitude mediana. Para a sub-bacia Perdizes a altitude mediana encontrada foi de $1.724 \mathrm{~m}$ (Figura 5) e para sub-bacia Fojo foi de $1.727 \mathrm{~m}$ (Figura 6).

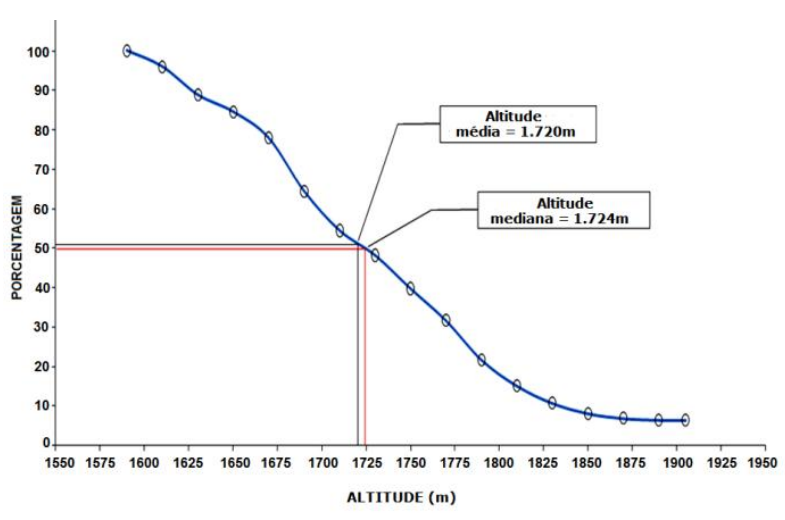

Figura 5. Curva hipsométrica da sub-bacia Perdizes.

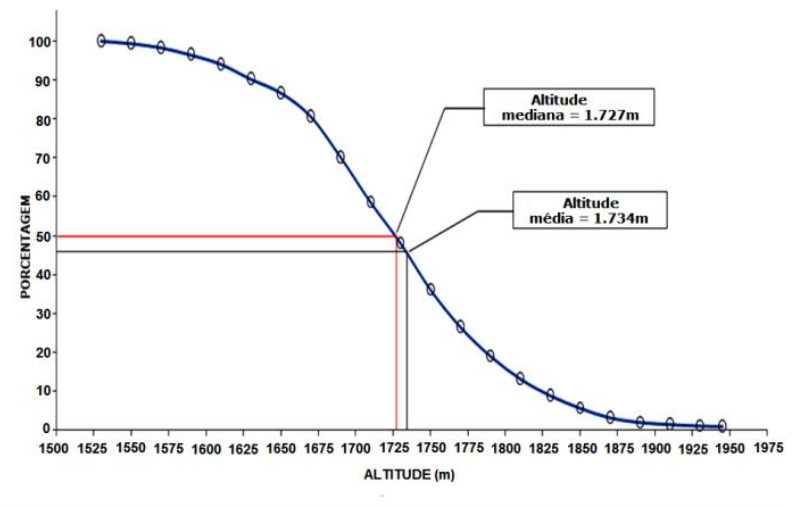

Figura 6. Curva hipsométrica da sub-bacia Fojo.

O índice de sinuosidade dos canais está relacionado à velocidade do escoamento nos canais de drenagem e, em síntese, sua relação com o solo em produzir erosão. Os índices de sinuosidade (Is) encontrados foram 1,33 para Perdizes e 1,43 para Fojo, os quais indicam que os canais de drenagem destas sub-bacias não têm forma retilínea, mas também, não podem ser considerados como sinuosos, ou seja, os canais têm uma forma transitória. Considerando que os solos dessas bacias são Cambissolos que possuem elevada capacidade de desagregação devido a elevada erodibilidade e forte limitação à trafegabilidade (Oliveira, 1999), é indicado o cuidado no uso desses solos principalmente quando à cobertura, especialmente para a urbanização e agricultura.

Em termos das características da rede de drenagem (Tabela 3) da área de estudo, os comprimentos totais dos canais principais foram de 8,81 km (Perdizes) e 9,64 km (Fojo). Ambas sub-bacias são de quarta ordem, sendo que a sub-bacia do Fojo possui 116 canais que apresentam comprimento total de $57,34 \mathrm{~km}$, enquanto a sub-bacia Perdizes possui 78 canais com um comprimento total de $44,27 \mathrm{~km}$.

A densidade de drenagem, que é uma das variáveis mais importantes para a análise morfométrica das bacias hidrográficas, representa o grau de dissecação topográfica, em paisagens elaboradas pela atuação fluvial, ou expressa a quantidade disponível de canais para o escoamento e o controle exercido pelas estruturas geológicas (Christofoletti, 1981).

Segundo Villela e Mattos (1975), a densidade de drenagem de bacias hidrográficas varia de $0,5 \mathrm{~km} / \mathrm{km}^{2}$ (para bacias com drenagem pobre) a $3,5 \mathrm{~km} / \mathrm{km}^{2}$ ou mais (para bacias excepcionalmente bem drenadas). Considerando os resultados obtidos nesse trabalho, a sub- 
bacia Perdizes apresenta densidade de drenagem alta $\left(D d=3,49 \mathrm{~km} / \mathrm{km}^{2}\right)$ enquanto que a Fojo enquadrou-se na classificação muito alta $\left(\mathrm{Dd}=4,1 \mathrm{~km} / \mathrm{km}^{2}\right)$, conforme classificação proposta por Beltrame (1994). Assim, os valores encontrados sugerem que há um elevado escoamento superficial associado a uma alta dissecação. Essa variável se relaciona diretamente com os processos climáticos atuantes na área estudada, os quais influenciam o fornecimento e o transporte de material detrítico ou indicam o grau de manipulação antrópica. Em outras palavras, para um mesmo tipo de clima, a densidade de drenagem depende do comportamento hidrológico dos solos e rochas. Assim, nos mais impermeáveis, as condições para ocorrer escoamento superficial são melhores, possibilitando a formação de canais e, consequentemente, aumentando a densidade de drenagem. O contrário acontece com rochas de granulometria grossa (Horton, 1945).

Outro importante parâmetro da qualidade da rede de drenagem de uma bacia é o Coeficiente de manutenção $(\mathrm{Cm})$, calculado pela relação inversa da densidade de drenagem e que fornece a área mínima necessária para a manutenção de um metro de canal de escoamento (Schumm, 1956). Esse dado permite representar qual seria a área necessária para a manutenção de um metro de curso fluvial perene. Assim, em termos de balanço hidrodinâmico das duas sub-bacias, os resultados obtidos indicam que são necessários 286,5 $\mathrm{m}^{2}$ de área para manter perene cada metro de canal na Perdizes contra $243,9 \mathrm{~m}^{2}$ de área para manter perene cada metro de canal da sub-bacia Fojo. Conforme se pode inferir a partir da Figura 1, a precipitação média mensal é de aproximadamente $150 \mathrm{~mm}$ e a precipitação média anual de aproximadamente $1.800 \mathrm{~mm}$ (Figura 2). Esses valores indicam que a área de estudo é bastante úmida durante o ano. No período menos chuvoso, de abril a setembro (Figura 2), a média mensal de chuva está em torno de $70 \mathrm{~mm}$, enquanto que no período mais úmido, de outubro a março, a média mensal de chuva atinge $230 \mathrm{~mm}$. Isso faz com que no período chuvoso, e em momentos de chuva intensas, haja condições mais propícias ao escoamento do que à infiltração. Dessa forma, o tipo de uso e cobertura pode influenciar na capacidade de produção de água da bacia, sendo importante o seus estados de conservação.

\section{CONCLUSÃO}

Com base na análise morfométrica pôde-se concluir que: as sub-bacias Perdizes e Fojo possuem, respectivamente, média e alta capacidade de formar novos cursos d'água; pelos valores do índice de circularidade não há concentração do deflúvio; e, em função dos valores do fator de forma associados ao coeficiente de compacidade, provavelmente as duas subbacias não são sujeitas a enchentes em condições normais de precipitação.

Com relação às características de relevo, conclui-se que: as sub-bacias Perdizes e Fojo possuem altas altitudes; canais com baixa sinuosidade transitória (nem retos, nem sinuosos); e valores elevados de amplitude altimétrica, da relação de relevo e do gradiente de canais o que indica que o relevo é montanhoso e que favorece o escoamento.

Com relação às características da rede de drenagem, pôde-se concluir que: as sub-bacias Perdizes e Fojo são respectivamente de alta e muito alta densidade de drenagem, sugerindo haver, em momentos de precipitação, um elevado escoamento superficial e uma alta dissecação associada e que ambas as bacias têm área suficiente para manter perenes os cursos d'água.

A área em estudo apresenta características físicas favoráveis ao abastecimento hídrico por ter clima úmido e por localizar-se em altitude elevada, por ter precipitação média mensal alta e por ser bem drenada. A sub-bacia Perdizes apresenta um estado de conservação preocupante por possuir área urbanizada 2,3 vezes superior à sub-bacia Fojo, possuir dois pontos de captação de água para abastecimento localizados praticamente em área urbanizada e não apresentar cobertura vegetal do tipo campo. 


\section{REFERÊNCIAS}

ALVES, J. M. P.; CASTRO, P. T. A. Influência de feições geológicas na morfologia da bacia do rio Tanque (MG) baseada no estudo de parâmetros morfométricos e análise de padrões de lineamentos. Revista Brasileira de Geociências, v. 33, n. 2, p. 117-127, 2003.

BELTRAME, A. V. Diagnóstico do meio ambiente físico de bacias hidrográficas: modelo de aplicação. Florianópolis: UFSC, 1994. 112 p.

CARDOSO, C. A.; DIAS, H. C. T.; SOARES, C. P. B.; MARTINS, S. M. Caracterização morfométrica da bacia hidrográfica do rio Debossan, Nova Friburgo - RJ. Revista Árvore, Viçosa, MG, v. 30, n. 2, p. 241-248, 2006. http://dx.doi.org/10.1590/S010067622006000200011

Comitê das bacias hidrográficas da Serra da Mantiqueira - CBH-SM. Relatório técnico preliminar zoneamento ambiental da unidade de gerenciamento de recursos hídricos - Mantiqueira (UGRHI 01). São Paulo, 2009. 143p.

CHRISTOFOLETTI, A. Análise morfométrica de bacias hidrográficas. Notícia Geomorfológica, v. 18, n. 9, p. 35-64, 1969.

CHRISTOFOLETTI, A. Geomorfologia fluvial: o canal fluvial. São Paulo: Edgard Blücher, $1981.313 \mathrm{p}$.

CURVELlO, R. T.; BATISTA, G. T.; TARGA. M. dos S. Estudo dos impactos da ocupação humana na microbacia do rio Batedor na serra da Mantiqueira no município de Cruzeiro, SP, Brasil. Revista Ambiente \& Água, Taubaté, v. 3, n. 1, p. 91-107, 2008. http://dx.doi.org/10.4136/ambi-agua.45

FREITAS, R. O. Textura de drenagem e sua aplicação geomorfológica. Boletim Paulista de Geografia, v. 11, p. 53-57, 1952.

HORTON, R. E. Erosional development of streams and their drainage basins: hydrophysical approach to quantitative morphology. Geological Society of America Bulletin, v. 56, n. 3, p. 275-370, 1945. http://dx.doi.org/10.1130/0016-7606(1945)56[275:EDOSAT]2.0.CO;2

INSTITUTO BRASILEIRO DE GEOGRAFIA E ESTATÍSTICA - IBGE. Cidades: censo 2010. Disponível em: <http://www.ibge.gov.br/cidadesat/topwindow.htm?1>. Acesso em: 21 nov. 2012.

INSTITUTO BRASILEIRO DE GEOGRAFIA E ESTATÍSTICA - IBGE. Mapa de solos do Brasil. Rio de Janeiro, 2002. Disponível em: <ftp://geoftp.ibge.gov.br/mapas/tematicos/ mapas_murais/solos.pdf $>$. Acesso em: 20 abr. 2008.

INSTITUTO DE PESQUISA TECNOLÓGICA - IPT. Relatório técnico sobre Campos do Jordão-SP. Relatório no 64.399. São Paulo, 2003.

KOBIYAMA, M. Ruralização na gestão de recursos hídricos em área urbana. Revista OESP Construção, São Paulo, ano 5, n. 32, p. 112-117, 2000. 
KRONKA, F. J. N.; NALON, M. A.; MATSUKUMA, M. M.; KANASHIRO, M. M.; YWANE, M. S. S.; LIMA, L. M. P. R.; et al. Monitoramento da vegetação natural e do reflorestamento no Estado de São Paulo. In: Simpósio Brasileiro de Sensoriamento Remoto, 12., 16-21 abril 2005, Goiânia. Anais... São José dos Campos: INPE, 2005. p. 1569-1576. Disponível em: <http://marte.dpi.inpe.br/col/ltid.inpe.br/sbsr/2004/ 11.01.10.06/doc/1569.pdf>. Acesso em: mar. 2008.

LANA, C. E.; ALVES, J. M. de P.; CASTRO, P. T. A. Análise morfométrica da bacia do Rio do Tanque, MG - BRASIL. REM: Revista Escola de Minas, Ouro Preto, v. 54, n. 2, p. 121-126, 2001. http://dx.doi.org/10.1590/S0370-44672001000200008

LIMA, W. P. Princípios de hidrologia florestal para o manejo de bacias hidrográficas. Piracicaba: ESALQ, 1986. 242p.

LOLLO, J. A. O uso da técnica de avaliação do terreno no processo de elaboração do mapeamento geotécnico: sistematização e aplicação na quadrícula de Campinas. 1995. Tese (Doutorado em Geotecnia) - Escola de Engenharia de São Carlos, Universidade de São Paulo, São Carlos, 1995.

NUNES, F. G.; RIBEIRO, N. C.; FIORI, A. P. Propriedades morfométricas e aspectosfísicos da bacia hidrográfica do Rio Atuba: Curitiba-Paraná. In: Simpósio Nacional de Geomorfologia, 6., 2006, Goiânia. Artigos... Goiânia: UFG, 2006.

OLIVEIRA, J. B. Solos do estado de São Paulo: descrição das classes registradas no mapa pedológico. Campinas: Instituto Agronômico, 1999. 112p. (Boletim Científico, 45).

REATTO, A.; SPERA, S. T.; CORREIA, J. R.; MILHOMEM, A. S. Caracterização dos solos e sua associação com as fitofisionomias em uma bacia hidrográfica: aspectos pedológicos e químicos. Planaltina: Embrapa Cerrados, 1999. 23p. (Boletim de Pesquisa, 8)

SÃO PAULO (Estado). Departamento de Águas e Energia Elétrica - DAEE. Banco de Dados Hidrometeorológicos do estado de São Paulo. Dados pluviométricos de Campos do Jordão. São Paulo, 1999. Disponível em: <http://www.sigrh.sp.gov.br/cgibin/bdhm2.exe/plu>. Acesso em: 18 dez. 2012.

SÃO PAUlO (Estado). Política Estadual de Recursos Hídricos. Lei $N^{\circ} 7663$, de 30 de dezembro de 1991. São Paulo, 1991. 19p. Disponível em: 〈http://www.daee.sp.gov.br〉. Acesso em: 04 jul. 2012.

SANTOS, A. M.; TARGA, M. S.; BATISTA, G. T.; DIAS, N. W. Florestamento compensatório com vistas à retenção de água no solo em bacias hidrográficas do município de Campos do Jordão, SP, Brasil. Revista Ambiente \& Água, Taubaté, v. 6, n. 3, p. 110-126, 2011. http://dx.doi.org/10.4136/ambi-agua.490

SETZER, J. Atlas climático e ecológico do estado de São Paulo. [S.1.]: Comissão Interestadual da Bacia Paraná-Uruguai, 1966. 61p.

SCHUMM, S. A. Evolution of drainage systems and slopes in badlands at Perth Amboy, New Jersey. Geological Society of America Bulletin, v. 67, n. 5, p. 597- 646, 1956. http://dx.doi.org/10.1130/0016-7606(1956)67[597:EODSAS]2.0.CO;2 
SILVA, L. G. T.; SILVA, B. N. R. da; RODRIGUES, T. E. Análise fisiográfica das várzeas do baixo Tocantins: uma contribuição ao manejo e desenvolvimento dos sistemas de uso da terra. Belém, PA: EMBRAPA Amazônia Oriental, 2002. 34 p. (Documentos, 149).

STRAHLER, A. N. Hypsometric (area-altitude) analysis of erosional topography. Geological Society of America Bulletin, v. 63, n. 11, p. 1117-1142, 1952. http://dx.doi.org/10.1130/0016-7606(1952)63[1117:HAAOET]2.0.CO;2

TONELlO, K. C.; DIAS, H. C. T.; SOUZA, A. L.; RIBEIRO, C. A. A. S.; LEITE, F. P. Morfometria da bacia hidrográfica da Cachoeira das Pombas, Guanhães - MG. Revista Árvore, Viçosa, MG, v. 30, n. 5, 2006. http://dx.doi.org/10.1590/S010067622006000500019

VILLELA, S. M.; MATTOS, A. Hidrologia aplicada. São Paulo: Mc Graw-Hill do Brasil, 1975.

WISLER, C. D.; BRATER, E. F. Hidrologia. Rio de Janeiro: Livro Técnico, 1964. 484 p. 